\title{
Phenomenology, Aesthetics, and Worldbuilding in Murasaki's The Tale of Genji and Tolkien's The Lord of the Rings
}

\author{
Farid Mohammadi \\ Universiti Malaya, Kuala Lumpur, Malaysia
}

\begin{abstract}
In this paper, I examine the theoretical aspects of worldbuilding in Murasaki's and Tolkien's imagined worlds and accentuate the role of aesthetic landscape creation through which spatio-temporal layers are negotiated. As a starting point, I refer to Thomas Ryba's Husserl, Fantasy and Possible Worlds (1990), where he evaluates the believability of secondary worlds via Husserlian phenomenology. To shed light on Ryba's statement that authors must be "adept at describing the qualities of characters and the world in which they live" (232) through the lens of engagement, I contend that critically acclaimed imagined worlds such as Heian Japan in The Tale of Genji (c.1000 A.D.) and Middle-earth in The Lord of the Rings (1954-1955) demonstrate two fundamental qualities: the physical environments possess aesthetic qualities and the emotional experience of the place is integrated into the fabric of worldbuilding, generating an aura of believability.
\end{abstract}

Keywords: Worldbuilding, Aesthetics, Phenomenology, Engagement, The Tale of Genji, The Lord of the Rings

Numerous authors and literary critics define the process of reading as an act of immersion. In Immersion and Other Short Novels (2002), for example, Gregory Benford explains that reading is a "voyage through a world imagined by another, taking in the imagery, ideas and subtleties of another mind" (1). In New Journalism (1973), Tom Wolfe argues that,

One's memory is apparently made up of millions of [sets of images], which work together on the Identikit principle. The most gifted writers are those who manipulate the memory sets of the reader in such a rich fashion that they create within the mind of the reader an entire world that resonates with the reader's own real emotions. The events are merely taking place on the page, in print, but the emotions are real. (1-52)

Therefore, the experience of complex emotions such as love, longing, nostalgia, and wonder in a literary text regardless of its genre, whether it is a monogatari that describes Japan's imperial court during the Heian period (794-1185) or a high fantasy set in a supernatural realm called Middle-earth, could evoke a sense of 
aesthetic immersion in the reader. One can argue that when we ponder the process of shaping a fictional world or how we experience one, what we identify as an immersion solely constitutes the first stage of the experience of the fictional world. That is to say, readers might become immersed in a secondary world, but only if that world possesses specific elements. In Husserl, Fantasy and Possible Worlds (1990), Thomas Ryba argues that believability is the most significant factor, as readers venture into the created secondary worlds "to feel that the story has been, in some sense, experienced as "lived time” (227). Ryba discusses Tolkien's statement regarding the secondary worlds in Tolkien's seminal lecture On Fairy-Stories (1947) who argued that,

What really happens [in the shaping of a fictional world] is that the story maker provides a successful 'sub-creation.' He makes a Secondary World, which your mind can enter. Inside it, what he relates is 'true': it accords with the laws of that world. You, therefore, believe it, while you are, as it were, inside. The moment disbelief arises, the spell is broken; the magic, or rather art, has failed. You are then out in the Primary World again, looking at the abortive Secondary World from the outside". (36-37)

Tolkien's statement is crucial because it explains a familiar phenomenon we experience whether we watch a movie or read a fictional story that happens in an imagined world. Tolkien thus discusses that believability can be achieved once the fictional world is constructed based on craft and artistry. Although Tolkien's proposed conditions seem simple, his points raise some phenomenological questions. For instance, what is artistry in the context of worldbuilding? How does it demonstrate itself in the recipient? And how is an author's artistry to be evaluated in the light of worldbuilding? However, before answering the mentioned questions to build upon Ryba's contentions on Tolkien's statement, I must discuss Husserlian phenomenology concerning the essence of fictional worlds.

\section{Husserl, Horizon, and Secondary Worlds}

It is a herculean task to offer a full-fledged definition of Husserl's Philosophical notion of horizon in a short essay, let alone a few paragraphs. The following lines can thus be no more than an initial attempt at explaining some angles of this complex term. According to Husserl, the term horizon is practically illustrated concerning the sense (Sinn) of an act of meaning. It is the sense's series of possible determinations. He argues that no sense of an act of meaning completely defines the object which it describes. Smith and McIntyre explain that the horizon of an act stands as "the set of possible acts whose Sinn are co-related and compatible with" (232) an act. Husserl further identifies two horizontal facets of meaning consists of 1) the horizon act of each meaning (noetic horizon) that is in agreement with a series of possible further conscious acts, which are in harmony with the 
primary act's sense; and 2) the object horizon of each meaning (noematic horizon) that is in agreement with a series of further possible characteristics or determinations of the object in harmony with the original act's sense.

As noetic acts suggest that particular objects could be of infinite variety, and distinctive characteristics could also possess infinite noematic meanings. That is to say, the Gegebenheitsweise (those meanings linked with their mode of presentation) could also possess infinite varieties. However, one must note that the primary defining factor could be the intentionality projected toward a specific object, which itself illustrates the noematic and the noetic dimensions/horizons. Both dimensions happen based on the conscious purpose of the object and then together transcends individual conscious actions. Husserl further elucidates that noematic and noetic dimensions/horizons can be categorized into internal and external horizons of the meaning-giving acts. While the internal dimensions/horizons stand for all the implications, moods, and conditions that are associated with the intended object, the external dimensions/horizons are all the meanings, moods, and conditions that affect the intended object in relation to its environment. Thus, the internal dimensions/horizons shape the nature of the object of the meaning, and the external dimensions/horizons form the context in which the meaning takes shape, and its object can happen.

One might then ask, what is the relationship between Husserlian terminologies to the concepts of immersion and worldbuilding discussed earlier? And how do the noetic dimensions/horizons contribute to our understanding of the believability of the imagined worlds? Ryba explains that "in writing a novel, the author constructs a tissue of sentences which in certain ways is no different from the narration contained in a factual report" (232). The author also supplements the chain of his sentences with several believable details of the world in which the fictional characters live. He then postulates that if the author's "art is great," or "if he is adept at describing the qualities of his characters and the world in which they live - then the reader cannot but help reactivate these descriptions and experience the described world and characters as if those characters and the world actually exist" (ibid.). In other words, what Ryba means is that the authors'/creators' artistry in the construction of believable secondary worlds depends on the way they form the interrelated tissues of meaning to develop noematic and noetic dimensions/horizons and the internal and external horizons of the meaninggiving acts in the constructed worlds.

Ryba discusses that "part of the skill [artistry] of any novelist" is to establish "a sense of reality with a minimum of words" (ibid.). Unfortunately, he does not provide further details on the authors" "art" or the necessary writing crafts that contribute to the sense of reality in an illustrated secondary world. He then adds, "by manipulating the antecedent, copresent and consequent horizons of the secondary world and its secondary realities [...] the reader either discovers a close analogy to things he has experienced or, not finding any close analogies in his own experience, finds the artfully constructed secondary world believable on its own terms as some distant extension of his own experience" (ibid.). It is worthy to note "the experience of the constructed 
world varies from reader to reader" (323) because the level of knowledge, intellect, and even cultural roots of readers vary. In this context, the external and internal dimensions/horizons "produce in readers experiences of the secondary worlds" (ibid.) that might be either similar or different from the real world of readers. For instance, Murasaki Shikibu's description of Japan's imperial court during the Heian period (794-1185) would invoke a different aesthetic experience or level of pleasure in a Japanese reader than in an English one; or J. R. R. Tolkien's illustration of the European medievalesque realm of Middle-earth in The Lord of the Rings would generate a different type of aesthetic pleasure and immersion in an English reader compared to a Japanese one.

Husserl discusses that a set of possible experiences described in a work of fiction could validate the believability of an imagined world. He then categorizes two types of objects in real and fictional worlds. One is the transcendental objects in the real world of the readers, and the other is the quasi-transcendental objects described in the fictional world. The former shapes the readers' perception of the actual world, yet the quasitranscendental objects are just the replicas of the transcendental objects. Considering the aesthetic insight and intention of the creator and the recipient regarding the presented fictional world, none of them would have the perception that the events within that fictional world could happen in the real world unless, as Ryba notes, "the reader has been tricked into thinking it is a work of history [...] as one is [seducing and the other] and is willingto-be seduced" (ibid.). In doing so, the creator, such as [an author or filmmaker], presents several "very vivid and consistent" (234) images based on the world of recipients to illustrate "a believable imaginary reality" (Ibid.). If the creator has been successful in "the execution of his art," the reader is willing to accept the imaginary reality as believable" (ibid.). This author-reader act of co-creation is "an immanent product of consciousness" (ibid.).

Ryba argues that "Husserl neglects an aspect of the intentionality which the reader brings to the novel" (235). I agree with Ryba when he contends that as readers, our observations, questions, and perceptions of an imaginary world are formed through our "tacit comparison between the real world and the secondary reality," and in this way, it is possible to consider an imagined world believable as it "could serve as an incomplete model of a possible world" (Ibid.). This view also supports Husserl's notion of a definite manifold "as compossible totalities of objects in general which are thought of as distinct only in empty formal generality" (8).

That is to say, "novels would seem to be manifolds occupying a level of generality somewhere between that of pure manifolds and that of definite manifolds" (235). It means a creator "leaves many of the aspects of his work undetermined, intending that the reader should flesh in the details," and "leaves open much that would otherwise be determined in a definite manifold which is intended as a description of the real world" (Ibid.). This process could happen when an author produces "consistency within the imaginary world [...] by borrowing descriptions that more properly belong to the real world" (ibid.). Ryba proposes that it is not the primary aim of the creator to construct "a definite manifold which describes the real world" but to present a "consistent [and] 
fragmentary, description of an imaginary world;" which means the creator is not "concerned with whether the actions and things described could actually take place in the real world," because he intends to persuade his readers "to believe that within the bounds of the imaginary world they are plausible" (236).

\section{Engagement}

To shed light on Ryba's unexplored dimension of a creator's "artistry," I propose that we can define the mentioned skillfulness concerning the transcendental and quasi-transcendental objects, which means how an author creates the space and place and sets the literary stage ready to place the characters/readers in an imagined world. Further, I contend that "artistry" depends on how an author/creator implements the aesthetic dimension of a secondary world, which would directly affect the process of immersion in the depicted world. Therefore, in terms of shaping imaginary worlds, I suggest that successful authors illustrate a highly detailed and aesthetic sensibility in creating the space and place of their imagined realms. Further, there is a direct connection between believability and the aesthetic dimension of the illustrated secondary world. To discuss further, I evaluate a passage in Murasaki's The Tale of Genji (c.1000 A.D.) and Tolkien's The Lord of the Rings (1954-1955) through the lens of engagement, which is an interdisciplinary critical term across literature, aesthetics, and philosophy.

Engagement functions as a process of discovery and immersion that can happen in almost every type of fictional world experience. It offers the possibility of experiencing the space and place through participation in noematic and noetic horizons. It also reminds us of what Walter Benjamin identified as "contemplative immersion" when he argued that works of art had been traditionally understood as possessing a sacred "aura," which itself evokes a "contemplative immersion" among the audience (Illuminations, 231). However, unlike Benjamin's discussion, engagement in this context is not a passive contemplation to make observers and participants lose their selves in the aesthetico-temporal properties of an object. In an aesthetic engagement, readers immerse themselves in the internal and external horizons of the meaning-giving acts in the secondary worlds to experience it phenomenologically where space, place, and atmosphere are venues in which they could bond with them. Then they actively ponder on the depicted world to form a direct attachment with the surrounding environments. Carlson contends that "active engagement" is vital for the rise of aesthetic experience, which involves "cognitive and emotional interaction between the appreciator and the object of appreciation" (197). He further elucidates that,

An important aspect of this engagement is a kind of dialogue between appreciator and object in which the latter explicitly or implicitly poses certain que stions or problems, and the former finds the answers or solutions. Such finding of answers or solutions typically takes the form of coming to realizations about the nature of the object of appreciation. This process of realizing is at the 
heart of aesthetic appreciation; it employs the imagination so as to produce that unique combination of admiration and awe that is central to aesthetic experience. (Aesthetics and the Environment, 197)

Carlson's statement highlights an aesthetic formalism shaped by an observation of the combination of colors, layout, arrangement, balance, and other features that he believed exist in a believable environment/world. In this context, engagement is an essential criterion for the approach of this paper in obtaining an assessment of Murasaki's and Tolkien's imagined worlds where characters are emotionally moved and melancholically contemplate the past, present, and possible future under the impact of the depicted world.

\section{Engagement, Melancholia, and Temporality}

As Maxine Greene contends, conscious "engagement with the arts does not occur naturally; it needs contemplation and dialogue" (The Audience Experience, 106). That is to say, for example, spectators of a painting or readers of a novel must actively assess "their experiences and, as a result, become cultural producers of meaning" (Immersive Theatres, 110), or co-creators of an imaginary depicted world. Gilles Deleuze proposes a similar statement by discussing that an effective engagement can transform and elevate a work of art as an experience to become a meaning (Immersive Theatres, 109). To discuss the conscious "engagement with the arts" and scrutinize the generation of aesthetic experiences towards the secondary worlds further, I propose evaluating Murasaki's The Tale of Genji (c.1,000 A.D.) and Tolkien's The Lord of the Rings (1954-1955) because of the extent to which they hold enough characteristics to be valued as artistic literary work s with powerful cultural influences. For example, a 1999 article in the Economist contended, "in Japan today, The Tale of Genji is as natural to the culture as Mount Fiji and the cherry blossom season, which testifies the novel's significance to the Japanese culture". Similarly, since its publication, The Lord of the Rings has gained a degree of cultural eminence that Tom Shippey, in J.R.R. Tolkien: Author of the Century (2001), described as a cultural phenomenon. There are abundant instances in Murasaki's Heian Japan and Tolkien's Middle-earth that can be evaluated via engagement. However, due to the word limit of the essay, I intend to evaluate one passage in The Tale of Genji and one section in The Lord of the Rings that I believe could stand as the microsome of both the authors' style of worldbuilding where the fabric of the illustrated world is constructed with aesthetico-poetic elements, which are the artistic products of the internal and external Horizons of the meaning-giving acts in both novels.

In The Tale of Genji, as the Japanese philosopher Nishida Kitarō notes, there is a profound sense of temporality. Nishida discusses that the expression "hirenzoku no renzoku," which can be translated as continuity in discontinuity, or discontinuous continuity, which reflects the Buddhist notion of "impermanence" ( mиjō) 
about which Michael F. Marra notes, "no one can bathe twice in the same water of the Kamo River since the water keeps flowing and changing (discontinuity); and yet, no one can deny the fact that the Kamo River continues to exist (continuity)" (Essays on Japan: Between Aesthetics and Literature, 327). Temporality and the sense of fading are profoundly embedded in the ways Murasaki describes the space, place, and atmosphere of the Heian court. In the opening part of The Sacred Tree chapter, we read:

It was over a reed plain of melancholy beauty that he made his way to the shrine. The autumn flowers were gone, and insects hummed in the wintry tangles. A wind whistling through the pines brought snatches of music to most wonderful effect, though so distant that he could not tell what was being played. Not wishing to attract attention, he had only ten outrunners, men who had long been in his service, and his guards were in subdued livery. He had dressed with great care. His more perceptive men saw how beautifully the melancholy scene set him off, and he was having regrets that he had not made the journey often. A low wattle fence, scarcely more than a suggestion of an enclosure, surrounded a complex of board-roofed buildings, as rough and insubstantial as temporary shelters...The fire lodge glowed faintly. It was all in all a lonely, quiet place, and here away from the world, a lady already deep in sorrow had passed these weeks and months. Concealing himself outside the north wing, he sent in word of his arrival. The music abruptly stopped and the silence was broken only by a rustling of silken robes. (150-151)

In the mentioned passage, Murasaki describes the place with a poetic sensibility. The juxtaposition of the aesthetic scenery with melancholic feelings and the composition of the shrine and natural environments conveys a delicate sense of beauty, which is blended with a sense of melancholia that can be felt via the characters' feelings. Further, the illustration of the autumn scenery and the description of the vanished flowers and whistling wind instill into the reader's mind a gradual sense of decline. There is also a feeling of regret or remorse over lost time; Genji's trip to the shrine, the autumn scenery, the unpleasant and interrupting sounds of the insects, and the image of the decaying flowers evoke the inescapable cycle of impermanence and the ephemerality of the earthly life. Further, the sense of movement in Genji's departure to the shrine and the passing of the season accentuates the melancholic feelings in the air and the sense of longing for the past. As Theodore de Bary notes, Genji demonstrates "mono no aware," which can be translated as "the sadness or pathos of things" (Passion and Poignancy in the Tale of Genji, 39), accompanied by a profound sense of beauty in the depicted world. Further, de Bary suggests, the expression of the journey to the shrine and the usage of "lonely," "silence," "bro ken" brings to mind "a spiritual experience that responds on one level to the Buddhist sense of impermanence and ephemerality and also the distinctive involvement with nature, which is a characteristic of Shinto school" (ibid. 
227).

Moreover, the comprehensive accounts of ceremonies are supplemented with detailed descriptions of clothes in specific seasons, and particular events such as the journey to the shrines, death, or sadness are accompanied by the autumn scenery throughout the book. That is to say, an aestheticized melancholia is integrated into the fabric of Murasaki's worldbuilding. Michael F. Marra also notes that "the notion of permanence underscores the idea of impermanence. Within the state of impermanence, in which everything changes, there is one thing that never changes: the fact that everything continuously changes, and never remains the same" (Essays on Japan: Between Aesthetics and Literature, 332). Indeed, immersing the reader in the Heian period and experiencing the aesthetic-poetic images associated with that era would generate a sense of nostalgia and longing for the glorious past and invoke a sense of nationalism in a modern Japanese reader.

Similarly, there is a sense of nostalgia generated from the fictional realm in Tolkien's mythic saga. In Lothlórien, the appreciation of the past and cultural heritage conservation takes an environmental dimension. Through the characters in Lórien, we encounter the harmonious integration of life in nature, particularly in connection with trees. Upon the arrival of the fellowship to the otherworldly landscapes, Frodo feels like he is walking in beauty as "he could smell the trees and the trodden grass. He could hear many different notes in the rustle of the leaves overhead, the river murmuring away on his right, and the thin clear voices of birds high in the sky. He felt the sun upon his face and hands when they passed through an open glade" (The Lord of the Rings, 349). In Lórien, Frodo experiences the space and place through all his senses except (at this point) sight. Tolkien specifies the sense of smell, hearing, and touch, and thus it seems that Frodo is completely immersed in his surroundings despite being blindfolded. Frodo then is prepared to follow the elf guide Haldir, he laid his hand upon the tree beside the ladder: "never before had he been so suddenly and keenly aware of the feel and texture of a tree's skin and of the life within it. He felt delight in wood and the touch of it, neither as forester nor as carpenter; it was the delight of the living tree itself" (The Fellowship of the Ring, 351). Tolkien's description of Frodo's engagement in the elven realm and his feelings towards the beauty of nature that he "felt delight in wood and the touch of it, neither as forester nor as carpenter; it was the delight of the living tree itself" (ibid.) is in perfect harmony with the notion of Disinterestedness as the first rule of Kant's analysis of beauty and judgment of taste.

Kant contends that an object is beautiful if we like it without any extra interest. Thus, our judgment, and perhaps engagement, must be free from any type of wish, intention, desire, social, material gain, and basically any form of personal or non-personal interests. In that case, our reflection on an object's beauty would be "pure," as Kant argues, and thus our judgment of beauty is shaped based on the voluntary engagement of our perception concerning the analysis of the object in question (Critique of the Power of Judgment, 85-67). Therefore, if the judgment and immersion are formed due to some interests that we have in the object in question, our judgment 
of beauty will not be pure and genuine. What Tolkien writes about Frodo's feelings indicates that due to the engagement with the otherworldly Lothlórien, Frodo's judgment is shaped by the experience of pleasure and delight solely formed out of the beauty of the place, free from any interest. Therefore, the admiration of the space, place, and atmosphere based on pure judgment backs the credibility of the contention that Frodo faces the rise of aesthetic experiences due to the sublimity of the landscape. The mentioned passage from The Lord of the Rings and its connection to Kant's notion of Disinterestedness is significant because it demonstrates the extent to which the aesthetic evaluation theories formulated for real-world landscapes can scrutinize textual/literary landscapes. Tolkien further describes the space and place in Lórien as follows:

Far away up on the hill they could hear the sound of singing falling from on high like soft rain upon leaves. They went along many paths and climbed many stairs, until they came to the high places and saw before them amid a wide lawn a fountain shimmering. It was lit by silver lamps that swung from the boughs of trees, and it fell into a basin of silver, from which a white stream spilled. Upon the south side of the lawn there stood the mightiest of all the trees; its great smooth bole gleamed like grey silk, and up it towered, until its first branches, far above, ope ned their huge limbs under shadowy clouds of leaves. (The Fellowship of the Ring, 354)

The sequence of the mentioned descriptions of Lothlórien highlights its ethereal and timeless atmosphere that is filled with pure beauty. The image of climbing the stairs among the golden and silver tree leaves side by side with the angelic elves reminds us of Edward Burne-Jones' 1880 painting The Golden Stairs. The PreRaphaelite painter Burne-Jones, who went to Exeter College like Tolkien, illustrated an image reflecting an ethereal mood and timeless beauty among pale-faced women/angels descending from a golden stair. Although the similarity is interesting, perhaps it is not surprising because when Tolkien enrolled at Exeter, it was famous for its Pre-Raphaelite alumni, such as William Morris and Edward Burne-Jones, "whose tapestries, murals, paintings, and tales of other worlds would influence Tolkien's own productions" (The Fellowship of the Ring, 64) to depict ethereal scenery across Middle-earth, especially in Lothlórien, which was one of his favorite locations in the whole of Middle-earth.

The descriptions of the space, place, and atmosphere are integrated into the fabric of the illustrations of the characters, which displays the extent to which Tolkienian landscapes and characters complement one another. Further, Sam's perception that "whether they have made the land or the land's made them, it is hard to say" (The Lord of the Rings, 455) suggests a complementary dependence of Middle-earth and characters with one another. Alfred Siewers asserts that "not only the immortal realms interlaced with the everyday world of physical experience and natural topography but they are interlaced with the sentient beings who inhabit them" (Tolkien's 
Cosmic-Christian Ecology, 143). Similarly, Michael Brisbois proposes that "the subtle magic that infuses the Elves is intertwined with the land they live in, suggesting they do not make clear distinctions between culture and nature" (Tolkien's Imaginary Nature, 197-216).

If in The Tale of Genji, the melancholic and poetic images of diminishment are displayed by the aesthetic images of the ephemerality of natural environments, for instance, through the cherry blossoms (Sakura) of spring, the autumn foliage of the crimson maple leaves $(K \bar{y} y \bar{o})$, the ever-flowing Uji River (Ujigawa), in The Lord of the Rings, the transient essence of the fictional world could be detected, for instance, via the images of the "golden blossoms and silver leaves" of the mallorn trees of Lothlórien, which is going to be diminished soon after the destruction of the Rings of Power, and the images of the melancholic society of the soon-to-be-extinct woodlands of Fangorn forest, or the green fields of the pastoral Shire. The aesthetically portrayed images thus demonstrate melancholic senses of temporality that generate an aesthetics of perishability in the depicted textual/literary worlds.

\section{Conclusion}

According to Ryba, Husserl proposed that "novelistic worlds are not about real possibilities [...] as whatever ontological status novels do possess, their intentionality is not such that they stand for possible worlds within the horizon of the world we experience" (Husserl, Fantasy, and Possible Worlds, 234). Although Ryba also emphasized that Husserl neglected the readers' role in the believability of a novel, he only explains that a reader could contribute to the process of evaluating the world of a novel "as an incomplete model" of the real world. Ryba proposes that by determining the imagined worlds as "models of possible worlds" we can utilize Husserl's notion of a definite manifold "as compossible totalities of objects in general which are thought of as distinct only in empty formal generality defined by determinate modalities of something-in-general" (The Rise of Modern Logic: from Leibniz to Frege, 305). The concept of definite manifolds also consists of "a finite number of concepts and propositions," which display “completely and unambiguously on lines of pure logical necessity the totality of all possible formations in the domain, so that, in principle [...] nothing further remains open within it" (235).

That is to say, assessing imagined worlds through the lens of definite manifolds allows focusing on various types of characteristics depicted in an imaginary world, and because of that, they could display similar or different types of worlds compared to the world of readers because "definite manifolds representing possibilities which have nothing to do with our possible world" (ibid.). Ryba elucidates that "an author, of necessity, leaves many of the aspects of his work undetermined, intending that the reader should flesh in the details, he leaves open much that would otherwise be determined in a definite manifold which is intended as a description of the real world;" and he achieves this by implementing a consistent illustration of familiar "descriptions that more 
properly belong to the real world" (ibid.) of readers. Ryba further proposes that "constructing such a world" requires a "consistent, but fragmentary, description of an imaginary world, as the primary mission is not to demonstrate real actions that "take place in the real world" but "to persuade the reader to believe that within the bounds of the imaginary world they are plausible" (Husserl, Fantasy, and Possible Worlds, 232). Ryba also discussed that fantasy stories "sustain their believability" only due to their consistency, and realistic historical fictions sustain their "believability from features borrowed from the primary world" (ibid.).

Although Ryba's statements seem fruitful, as I discussed previously, he does not explain what he means by "adept author," and later, he does not provide further explanation on the qualities that could contribute to the consistency of an imagined world either. I contend that both Murasaki and Tolkien demonstrate poetic and delicate images of natural environments in their respective imagined worlds. Their illustration of the trees, streams, seasons, buildings, characters, to name but a few, have the capacity to add an aesthetic layer to the textual/literary world, which invokes sentiments of nostalgia and melancholia. To explore the contours of Murasaki's and Tolkien's aesthetic landscape creation in the textual/literary realms of the Japanese Heian period and Middle-earth, I particularly employed the notion of literary engagement and focused on the external qualities of the world, the elements that characterize the scenery in question and the factors that stimulate the imagination of characters in the illustrated locations. The overall conclusion I have arrived at through my discussions is that the mentioned textual/literary worlds demonstrate aesthetic and melancholic dimensions. Thus, aesthetic sensibility could be a crucial factor among the artist traits of authors. Aesthetico-poetic imageries in the mentioned texts stand as general signs of a bygone era, ones that make visible impressions of the aesthetic and temporal images of a world that no longer exists, and both authors aesthetically draw our attention to this melancholic truth so that readers co-create the bygone eras cognitively.

Paying attention to the noematic and noetic dimensions/horizons that can be categorized into internal and external horizons of the meaning-giving acts also indicates that Murasaki and Tolkien stimulate the imagination of their characters/readers through the beautiful, picturesque, and melancholic illustration of space, place, and atmosphere that could lead to the rise of aesthetic responses and experiences towards the depicted space and place and their decorative elements such as the trees, seasons, buildings, to name a few. Ultimately, I propose that the worldbuilder or creator of an imaginary world could possess various skills and crafts in the shaping of a secondary world. Successful worldbuilders such as Murasaki and Tolkien display the ability to illustrate aesthetic-poetic landscapes, which in this context could generate spaces of contemplation in their fictional worlds, which itself contributes to the sense of believability. As Ryba suggests, "a novel is more or less believable depending upon whether one can put parts of the real world and its horizon of possibility into a one to one relationship with parts of the novel's quasi-world and quasi-horizon" (236); however, the successful fictional worldbuilders display aesthetic dimensions that could create symbiotic emotional connections with 
readers and the depicted worlds.

\section{Works Cited}

Benford, Gregory. Immersion \& Other Short Novels. Five Star, 2002.

Benjamin, Walter. Illuminations. London, England: Vintage Digital, 2015. Print.

---. The Work of Art in the Age of MechanicalReproduction. Trans. J. A. Underwood. Harlow, England: Penguin Books, 2008. Print.

Brisbois, Michael J. “Tolkien's Imaginary Nature: An Analysis of the Structure of Middle-Earth.” Tolkien Studies 2.1 (2005): 197-216. Print.

Carlson, Allen. Nature and Landscape: An Introduction to Environmental Aesthetics. Columbia University Press, 2009.

Clark Jr, Walter H, et al. "The Cognition of the Literary Work of Art." Journal of Aesthetics and Art Criticism 33.2 (1974): 220. Print.

Flieger, Verlyn, and Douglas A. Anderson. Tolkien on Fairy-Stories. London, England: HarperCollins, 2014.

Gabbay, D. M., and John Woods. The Rise of Modern Logic: From Leibniz to Frege. Elsevier, 2004. Print.

Geniusas, Saulius. The Origins of the Horizon in Husserl's Phenomenology. New York, NY: Springer, 2012.

Guyer, Paul, ed. Kant's Critique of the Power of Judgment: Critical Essays. Lanham, MD: Rowman \& Littlefield, 2003.

Hume, Nancy G., ed. Japanese Aesthetics and Culture: A Reader. Albany, NY: State University of New York Press, 1995.

Husserl, Edmund. Cartesian Meditations: An Introduction to Phenomenology. Springer Philosophy, 2013.

---. Ideas: General Introduction to Pure Phenomenology. Routledge, 2015.

Kemal, Salim. Kant's Aesthetic Theory: An Introduction. Palgrave Macmillan, 2016.

Machon, Josephine. Immersive Theatres: Intimacy and Immediacy in Contemporary Performance. Macmillan International Higher Education, 2013.

Marra, Michael. Essays on Japan: Between Aesthetics and Literature. Brill Academic, 2010.

Mohanty, Jitendra N. "Intentionality and 'Possible Worlds: Husserl and Hintikka” Phaenomenologica (1982): 25-44. Print.

Murasaki, Shikibu. The Tale of Genji. Translated by E. G. Seidensticker, Penguin Books, 1980.

Ryba, Thomas. "Husserl, Fantasy and Possible Worlds.” Phenomenology and Aesthetics, Springer Netherlands, 
(1990): 227-237. Print.

Siewers, Alfred K. “Tolkien's Cosmic-Christian Ecology: The Medieval Underpinnings.” Tolkien's Modern Middle Ages (2005): 139-153.

Smith, David Woodruff, and Ronald McIntyre. Husserl and Intentionality: A Study of Mind, Meaning and Language. Kluwer Academic, 1984.

Theodore de Bary, William. "Passion and Poignancy in The Tale of Genji." Finding Wisdom in East Asian Classics. Columbia University Press, 2011.

---. The Vocabulary of Japanese Aesthetics. State University of New York Press, 1995.

Tolkien, J. R. R. The Lord of the Rings. HarperCollins, 2014.

---. Tolkien Reader. Ballantine Books, 1972. Print.

Walmsley, Ben. Audience Engagement in the Performing Arts: A Critical Analysis. Springer Nature, 2019.

Wolfe, Tom. New Journalism. Picador, 1975. Print.

Zdebik, Jakub. Deleuze and the Diagram: Aesthetic Threads in Visual Organization. Bloomsbury Academic, 2014. 